\title{
Physicochemical Characterization and Dissolution Study of Solid Dispersions of Ketoconazole with Nicotinamide
}

\author{
Amit Kumar AgGarwaL* and Shweta JaIN \\ G.H.G. Khalsa College of Pharmacy; Gurusar Sadhar-141104, Distt. Ludhiana, Punjab, India. \\ Received December 23, 2010; accepted February 12, 2011; published online February 16, 2011
}

\begin{abstract}
Purpose: The aim of the present study was to improve the solubility and dissolution rate of a poorly watersoluble drug ketoconazole using solid dispersion technique. Methods: Solid dispersions of ketoconazole were prepared in ratios of $90: 10,70: 30,50: 50,30: 70$ and $10: 90$ by the melting method using nicotinamide as carrier. These solid dispersions were characterized by differential scanning calorimetry (DSC), powder X-ray diffraction (XRD) and Fourier transform infrared (FT-IR) spectroscopy to ascertain if there were any physicochemical interactions between drug and carrier that could affect dissolution. Solubility and dissolution studies were conducted with pure ketoconazole, physical mixtures and solid dispersions. Results: Solubility studies indicated that nicotinamide increased significantly the solubility of ketoconazole in water. The Gibbs free energy $\left(\Delta G_{\text {tr }}^{\circ}\right)$ values were negative indicating the spontaneous nature of ketoconazole solubilization, and it decreased with increase in concentration of the carrier, demonstrating that the reaction became more favorable as the concentration of the carrier increased. The cumulative release of ketoconazole within $120 \mathrm{~min}$ from solid dispersion at a drug-tonicotinamide ratio of $10: 90$ (w/w) was 6 times higher than the pure drug in phosphate buffer of pH 6.8. Conclusion: Solid state characterization indicated that there is no interaction between ketoconazole and nicotinamide in the solid state. In contrast to the very slow dissolution rate of pure ketoconazole, the dispersion of the drug in nicotinamide considerably enhanced the dissolution rate. The drug dissolution rate was highest at a drug-tonicotinamide ratio of $10: 90(\mathrm{w} / \mathrm{w})$.
\end{abstract}

Key words Ketoconazole; nicotinamide; solid dispersion; solubility; dissolution

Ketoconazole (Fig. 1) is an imidazole antifungal agent which is administered both orally and topically. It is reported to be orally active in the treatment of systemic blastomycosis, candidiasis, coccidioidomycosis, histoplasmosis, paracoccidioidomycosis, and tinea of skin and nails. However, due to its erratic oral absorption, it should not be used in the treatment of life-threatening fungal infections. ${ }^{1)}$ Due to its dissolution and absorption properties, ketoconazole (KET) is classified in the Biopharmaceutics Classification Scheme as a class II drug, since it has a high permeability, but a solubility in aqueous media which is insufficient for the whole dose to be dissolved in the gastro-intestinal fluids under normal conditions. ${ }^{2}$ KET was selected as a model drug, which was the first antifungal agent in a series of azole derivatives used to treat a wide variety of superficial and systemic mycotic infections. ${ }^{3)}$ It is known that KET has significant individual variations and a low bioavailability when given orally, due to its low solubility.

The poor dissolution characteristic of relatively insoluble drugs has long been and still remains a problem to the pharmaceutical industry because the dissolution rate could be the rate-limiting process in the absorption of a drug from a solid dosage form. Therefore, efforts to increase drug dissolution are often needed. Methods available to improve dissolution include salt formation, micronization and addition of solvent or surface active agents. Solid dispersion (SD) is one of such methods and it involves a dispersion of one or more active ingredients in an inner carrier or matrix in solid state prepared by melting, dissolution in solvent or melting-solvent method. Dissolution rate vary with the manufacturing methods or change in the carrier. The same drug may have better dissolution with melting method in one carrier and with solvent method in another carrier. Every method has some advantages and some disadvantages. We preferred the melting method because in solvent method, it is difficult to remove the solvent completely and most of the solvents are toxic. Moreover, there is not a large difference in the melting point of KET and nicotinamide. Solid dispersion technique is used to enhance the dissolution rate and bioavailability of poorly soluble drugs. ${ }^{4,5}$ Solid dispersion of KET in polyvinylpyrrolidone $^{6}$ and inclusion complexes with $\beta$-cyclodextrin ${ }^{7)}$ are reported. However, there is no report on the preparation and evaluation of ketoconazole and nicotinamide solid dispersions.

Nicotinamide (NIC) is a hydrotropic agent used to enhance the aqueous solubility of diazepam, ${ }^{8)}$ progesterone, ${ }^{8)}$ anticancer nucleosides, ${ }^{9)}$ flurbiprofen ${ }^{10)}$ and many more drugs. ${ }^{11,12)}$ Nicotinamide has also been used as a carrier to enhance the dissolution rate of indomethacin. ${ }^{13-16)}$ Two advantages that make it a very attractive agent when used as a hydrotrope; it has US Food and Drug Administration approval status, and very low toxicity. ${ }^{17)}$

In the present work, KET-NIC solid dispersions were studied with the objective of improving the dissolution rate of ketoconazole. The drug-carrier interactions in the liquid and solid-state were studied by using phase solubility analysis, dissolution studies, powder X-ray diffraction (PXRD), Fourier transform infrared spectroscopy (FT-IR), and differential scanning calorimetry (DSC). Melting method was employed to obtain solid dispersions of KET with NIC in different weight ratios.

\section{Experimental}

Materials Ketoconazole was supplied by Haustus Biotech Pvt. Ltd. (Himachal Pradesh, India) and nicotinamide was purchased from Loba Chemie Pvt. Ltd. (Mumbai, India). Triple distilled water was used throughout the experiments. All other chemicals were of reagent grade and used without further purification.

Preparation of Solid Dispersions and Physical Mixtures Solid dispersion samples in KET : NIC ratios of 9: 1 (SD1), $7: 3$ (SD2), $5: 5$ (SD3), $3: 7$ 
(SD4) and 1:9 (SD5) were prepared by the fusion method. Ketoconazole and nicotinamide in the required ratios were homogeneously mixed and fused in a porcelain dish over a calibrated hot plate $\left(120-130^{\circ} \mathrm{C}\right)$. The fused masses were solidified on an ice bath under constant stirring. These masses were pulverized and sifted through 100-mesh sieve and stored in a desiccator over fused calcium chloride.

Physical mixture samples in KET : NIC ratios of 9: 1 (PM1), 7:3 (PM2), 5: 5 (PM3), 3:7 (PM4) and 1:9 (PM5) were prepared by homogeneously mixing the ingredients and sifted through 100-mesh sieve.

Content Uniformity Analysis Drug content of the solid dispersions (SDs) and physical mixtures (PMs) were evaluated in methanol using ultraviolet (UV) spectrophotometer (Perkin Elmer, U.S.A.) at $231 \mathrm{~nm}$. The absorbance was recorded against a blank solution of an equivalent amount of nicotinamide (in methanol) to overcome the absorbance of nicotinamide at $231 \mathrm{~nm}$.

Saturation Solubility and Phase Solubility Studies Weighed amounts of pure KET, SDs and PMs, each sample equivalent to $200 \mathrm{mg}$ of drug, were separately introduced into $25-\mathrm{ml}$ stoppered conical flasks containing $10 \mathrm{ml}$ of distilled water. The sealed flasks were shaken on a water bath shaker for $72 \mathrm{~h}$ at $37^{\circ} \mathrm{C}$. An aliquot was passed through $0.2-\mu \mathrm{m}$ filter (Millipore, Bangalore, India), and the filtrate was suitably diluted and analyzed on a UV spectrophotometer (Perkin Elmer) at $231 \mathrm{~nm}$. The samples were studied in triplicate for saturation solubility; the objective was to study the effect of NIC on the aqueous solubility of KET.

The phase solubility studies were conducted as per the method reported by Higuchi and Connors. ${ }^{18)}$ Excess KET was added separately into $25-\mathrm{ml}$ stoppered conical flasks containing $10 \mathrm{ml}$ of aqueous solution $(0.02-0.09 \mathrm{M}$ or $0-1 \% \mathrm{w} / \mathrm{v}$ ) of NIC. The flasks were sealed and shaken on a water bath shaker at $37^{\circ} \mathrm{C}$ for $72 \mathrm{~h}$. An aliquots were filtered through membrane filters $(0.2 \mu \mathrm{m}$, Millipore), and filtrates were suitably diluted and analyzed at $231 \mathrm{~nm}$. All the data are the average of three determinations. The complexation constants $(\mathrm{K})$ were estimated by (a) a previously published complexation scheme and linear equation with an approximation (Higuchi and Conners) ${ }^{18)}$ (b) an exact solution of the equation with no approximation, and (c) a linear regression on (b) and parabolic or polynomial regression analysis on (a) and (b).

Solubilization Efficiency The ratios of the solubility obtained with PMs or SDs to the intrinsic solubility $\left(S_{\mathrm{o}}\right)$ were calculated. These ratios were used to compare the relative solubilization efficiency of SDs to that of the PMs.

Calculation of Complexation Constants from the Phase Solubility The solubility of KET in triple distilled water was $0.044 \mu \mathrm{g} / \mathrm{ml}$. The solubility increased in the presence of NIC (Fig. 1) but the increase in solubility was not a linear function of nicotinamide concentration, suggesting the formation of higher order complexes.

For a system in which $1: 1$ and $1: 2$ complexes of a substrate $S$ with a ligand $L$ are formed, complexation is represented by Chart 1,

$$
K_{1: 1}=\frac{[S L]}{S_{o}[L]}
$$

and

$$
K_{1: 2}=\frac{\left[S L_{2}\right]}{[S L][L]}
$$

In Eqs. 1 and 2, $S_{o}$ is the equilibrium solubility of the substrate, $[L]$ is the concentration of free ligand, $[S L]$ is the concentration of the $1: 1$ complex, $\left[S L_{2}\right]$ is the concentration of the $1: 2$ complex, and $K_{1: 1}$ and $K_{1: 2}$ are the $1: 1$ and $1: 2$ complexation constants, respectively. The complexation constants can be determined by the following equation. ${ }^{18}$

$$
\left[S_{t}\right]=\left[S_{o}\right]+K_{1: 1} S_{o}[L]+K_{1: 1} K_{1: 2} S_{o}[L]^{2}
$$

In Eq. 3, $\left[S_{t}\right]$ is the total KET concentration in solution. If the extent of complexation is fairly small, it may be permissible to use $[L] \sim\left[L_{t}\right]$, thus giving Eq. 4:

$$
\left[S_{t}\right]=\left[S_{o}\right]+K_{1: 1} S_{o}\left[L_{t}\right]+K_{1: 1} K_{1: 2} S_{o}\left[L_{t}\right]^{2}
$$

From Eq. 4, $K_{1: 1}$ and $K_{1: 2}$ can be determined from constants calculated from a computerized parabolic fit of the data.

The values of $K_{1: 1}$ and $K_{1: 2}$ can alternatively be determined by linear regression on an algebraic manipulation of Eq. 4 by dividing both sides by $\left[L_{t}\right]$, thus obtaining the following equation

$$
\frac{\left[S_{t}\right]-S_{o}}{\left[L_{t}\right]}=K_{1: 1} S_{o}+K_{1: 1} K_{1: 2} S_{o}\left[L_{t}\right]
$$

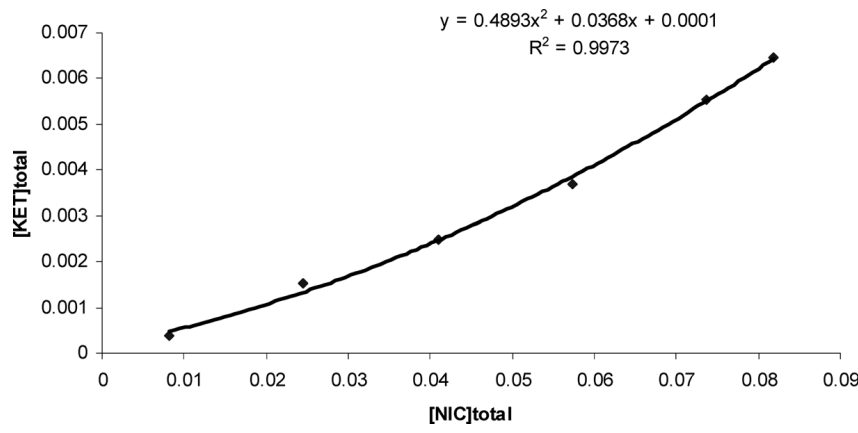

Fig. 1. Molar Solubility of Ketoconazole vs. Concentration of Nicotinamide

$$
\begin{aligned}
S+L \stackrel{K_{1: 1}}{\rightleftharpoons} S L \\
S L+L \stackrel{K_{1: 2}}{\rightleftharpoons} S L_{2}
\end{aligned}
$$

Chart 1

If the assumption $[L] \sim\left[L_{t}\right]$ is not valid, then $K_{1: 1}$ and $K_{1: 2}$, could be represented in terms of $\left[S_{t}\right]$ and $\left[L_{t}\right]$ and an exact solution can be derived by one of the following equations:

$$
\begin{aligned}
& {\left[S_{t}\right]=S_{o}+[S L]+\left[S L_{2}\right]} \\
& {\left[L_{t}\right]=[L]+[S L]+2\left[S L_{2}\right]} \\
& {[L]=\left[L_{t}\right]-[S L]-2\left[S L_{2}\right]}
\end{aligned}
$$

One can easily measure $\left[L_{t}\right],\left[S_{t}\right]$, and $S_{o}$ and express $[S L]$ and $\left[S L_{2}\right]$ as a function of the unknown $[L]$ and the complexation constants so that they can be determined directly, with no assumptions.

Representing Eq. 8 in terms of $[L], K_{1: 1}$, and the known quantities $\left[L_{t}\right]$, $\left[S_{t}\right]$, and $S_{o}$, and substituting for $\left[S L_{2}\right]$ from Eq. 6 results in the following:

$$
[L]=\left[L_{t}\right]-[S L]-2\left\{\left[S_{t}\right]-S_{o}-[S L]\right\}
$$

$$
[L]=\left[L_{t}\right]+[S L]-2\left(\left[S_{t}\right]-S_{o}\right)
$$

Substituting for $[S L]$ from Eq. 1 into Eq. 10 gives the following

$$
[L]=\left[L_{t}\right]+K_{1: 1} S_{o}[L]-2\left(\left[S_{t}\right]-S_{o}\right)
$$

Solving for $[L]$ yields the following:

$$
[L]=\frac{\left[L_{t}\right]-2\left(\left[S_{t}\right]-S_{o}\right)}{1-K_{1: 1} S_{o}}
$$

Substituting Eq. 12 into Eq. 3 gives the following:

$$
\begin{aligned}
{\left[S_{t}\right]-S_{o}=} & \frac{K_{1: 1} S_{o}}{1-K_{1: 1} S_{o}}\left\{\left[L_{t}\right]-2\left(\left[S_{t}\right]-S_{o}\right)\right\} \\
& +\frac{K_{1: 1} K_{1: 2} S_{o}}{\left(1-K_{1: 1} S_{o}\right)^{2}}\left\{\left[L_{t}\right]-2\left(\left[S_{t}\right]-S_{o}\right)\right\}^{2}
\end{aligned}
$$

The values of $K_{1: 1}$ and $K_{1: 2}$ for the complexation of KET with NIC were determined by fitting a plot of $S_{t}$ versus $\left\{\left[L_{t}\right]-2\left(\left[S_{t}\right]-S_{o}\right)\right\}$ with a parabola based on Eq. 13 and using the constants of the fitted equation.

Alternatively, a linear regression was performed on the linear form of Eq. 13 shown below:

$$
\frac{\left[S_{t}\right]-S_{o}}{\left[L_{t}\right]-2\left(\left[S_{t}\right]-S_{o}\right)}=\frac{K_{1: 1} S_{o}}{1-K_{1: 1} S_{o}}+\frac{K_{1: 1} K_{1: 2} S_{o}}{\left(1-K_{1: 1} S_{o}\right)^{2}}\left\{\left[L_{t}\right]-2\left(\left[S_{t}\right]-S_{o}\right)\right\}
$$

Goodness of fit parameters for both the linear and parabolic regressions was determined. The values of $K_{1.1}$ and $K_{1.2}$ and the fit parameters are given in Table 3. The fit parameters utilized in this study were the multiple $R^{2}$ and $F$ values, where $R^{2}$ is the goodness-of-fit correlation coefficient and the $F$ value is the ratio of the regression mean square to the residual mean square and is a measure of the significance of the fit as a whole. The closer $R^{2}$ approaches 1 and the higher the $F$ value, the better the fit.

Dissolution of SDs and PMs In vitro dissolution tests of the pure drug, 
powdered SDs, and PMs (equivalent to $0.1 \mathrm{~g} \mathrm{KET)} \mathrm{were} \mathrm{performed} \mathrm{in} \mathrm{tripli-}$ cate, using the dissolution apparatus (Electrolab) type II paddle method at $37 \pm 0.5^{\circ} \mathrm{C}$ for $2 \mathrm{~h}$, with a stirring rate of $50 \mathrm{rpm}$, in $900 \mathrm{ml}$ of a dissolution medium of enzyme-free simulated intestinal fluid $(\mathrm{pH} 6.8 \pm 0.1)$. Dissolution samples were collected at 5,10,15, 20, 25, 30, 45, 60 and $120 \mathrm{~min}$, with replacement of an equal volume of temperature equilibrated dissolution medium. The samples were filtered through a $0.2 \mu \mathrm{m}$ membrane filter, and the concentration of the drug was determined by UV spectrophotometry at $231 \mathrm{~nm}$. Blank experiments with NIC were also performed at the same wavelength for correction. All samples were analyzed in triplicate. Dissolution efficiencies after 15, 30, 60 and 120 min were calculated. Mean Dissolution Time was also calculated.

Release Profiles Comparison A model-independent approach was used for comparing the dissolution profiles of pure drug, PMs and solid dispersions. Model-independency described by Rescigno, ${ }^{19)}$ in general would generate results for which the values do not depend on the selection of the specific parameter for filling the data, but are dependent on the sampling times $t_{1}, t_{2} \cdots t_{n}$

In the time point/ratio test approach, mean dissolution times ( $\mathrm{MDT}_{15 \%}$ and $\mathrm{MDT}_{50 \%}$ ) were calculated for each formulation dissolution measurements. Application of MDT provides more accurate drug release rate as compared to the $t_{x \%}$ (time for $x \%$ drug dissolved) approach and is determined as the sum of the individual periods of time during which a specific fraction of the total dose is released. ${ }^{20)}$

The following equation may be used to calculate the MDT for each percentage point:

$$
\text { MDT }=\sum_{i=1}^{n} t_{\text {mid }} \Delta M / \sum_{i=1}^{n} \Delta M
$$

Where $i$ is the sample number, $n$ is the number of dissolution sample time, $t_{\text {mid }}$ is the time at the midpoint between $i$ and $i-1$, and $\Delta M$ is the additional amount of the drug which was dissolved in the period of time between $i$ and $i-1$.

The MDT is a measure of the rate of the dissolution process.

In the pairwise approach, determination of a "difference factor, $f_{1}$ " and "similarity factor, $f_{2}$ " using the mean percentage released values can be performed by using following equations.

$$
\begin{aligned}
& f_{1}=\left\{\frac{\sum_{t=1}^{n}\left|R_{t}-T_{t}\right|}{\sum_{t=1}^{n} R_{t}}\right\} \times 100 \% \\
& f_{2}=50 \log \left\{\left[1+\frac{1}{n} \sum_{t=1}^{n} w_{t}\left(R_{t}-T_{t}\right)^{2}\right]^{-0.5} \times 100\right\}
\end{aligned}
$$

where $n$ is the number of withdrawal points, $R_{t}$ is the percentage dissolved of reference at the time point $t, T_{t}$ is the percentage dissolved of test at the time point $t$, and $w_{t}$ is optional weight at time $t$ (for the entire study, the value of $w_{t}$ is assumed to be 1$)$.

The $f_{2}$ value between 50 and 100 suggests that the dissolution profiles are similar and as the values becomes smaller the dissimilarity between release profiles increases.

Moore and Flanner described a fit factor $f_{1}$ as the relative error between two dissolution profiles. "It approximates the percent error between two curves." ${ }^{21)}$ The percent error is zero when the test and reference profiles are identical and increases proportionally with the dissimilarity between the two profiles.

Also, the dissolution efficiency was used to compare in-vitro dissolution of different formulations using following equation ${ }^{22)}$ :

$$
D E_{t}=\left[1+1 / \lambda \cdot\left(e^{-\lambda}-1\right)\right] \cdot 100
$$

where $\lambda=4.606-\ln (100-f)$ and $f$ is the percentage of drug dissolved at time $t$.

The relative dissolution rate $\left(\mathrm{RDr}_{5}\right)$ data of the different samples were also calculated by determining the amount of KET dissolved from particular sample and normalizing for the amount of drug dissolved from pure drug sample over the same time interval ( $5 \mathrm{~min}$ ).

Physical Characterization of PMs and SDs. Powder X-Ray Diffraction The scanning powder X-ray diffraction patterns of KET, NIC and their SDs and PMs were obtained on a powder X-ray diffractometer (X'PERT-PRO) under the following conditions: Ni-filtered $\mathrm{Cu} K \alpha$ radiation; $45 \mathrm{kV}$ voltage: $40 \mathrm{~mA}$ current, scan speed $2 \% \mathrm{~min}$ in terms of $2 \theta$ angle. These PXRD were used to characterize the physical state of the drug in the SDs and PMs. Samples were scanned over a range of $2 \theta$ values, from 5 to $50^{\circ}$, at the scan rate of $2.0^{\circ} / \mathrm{min}$, for $30 \mathrm{~min}$ per sample.

Differential Scanning Calorimetry The thermal behavior of KET, NIC, PMs and SDs were investigated using a NETZSCH, DSC 204 F1 phoenix (U.S.A.). Accurately weighed samples $(10 \mathrm{mg})$ were placed in standard aluminum pans and covered with a pierced lid. Dry nitrogen was used as the pure gas, at flow rate $50 \mathrm{ml} / \mathrm{min}$. The thermo-grams were obtained by heating the samples at a rate of $10 \mathrm{~K} / \mathrm{min}$ from $50^{\circ} \mathrm{C}$ temperature to $250{ }^{\circ} \mathrm{C}$.

Fourier Transform Infrared (FT-IR) Spectroscopy In order to collect the spectra using Perkin-Elmer FT-IR spectrometer, small amount $(5 \% \mathrm{w} / \mathrm{w})$ of each material (KET, NIC, PMs and SDs) was compressed in $\mathrm{KBr}$ pellets. To avoids the effect of moisture all samples were dried overnight in a dessicator. The IR spectra, in transmittance mode, were obtained in the spectral region of $4000-500 \mathrm{~cm}^{-1}$ using a resolution of $2 \mathrm{~cm}^{-1}$ and 4 scans. A polystyrene filer was used to check the spectrophotometer calibration and $\mathrm{KBr}$ pellet was used as reference.

\section{Results}

Low standard deviation values in percent drug content ensured uniformity of drug content in each sample.

Content Uniformity Analysis KET assay in all SDs was almost $100 \%$ and the percentage yield was greater than $97 \%$ (data not shown).

The content of KET in all the PMs and SDs was found to vary from 97.23 to $100.39 \%$ of the claimed amount of drug (Table 1) and percentage yield was greater than $98 \%$ (data not shown).

Solubilization Efficiency of Nicotinamide The solubility enhancements $\left(S_{c} / S_{o}\right)$ obtained from the PMs and SDs for KET are presented in Table 1.

Interaction between Ketoconazole and Nicotinamide in Water An indication of the process of transfer of KET from pure water to aqueous solution of NIC was obtained from the values of Gibbs free energy change. The Gibbs free energy of transfer $\left(\Delta G_{\text {tr }}^{\circ}\right)$ of KET from pure water to aqueous solutions of NIC was calculated using the following equation:

$$
\Delta G_{\mathrm{tr}}^{\circ}=-2.303 R T \log \left(\frac{S_{c}}{S_{o}}\right)
$$

where $S_{c} / S_{o}$ is the ratio of molar solubility of KET in aqueous solution of NIC to that of pure water.

The obtained values of $\Delta G_{\mathrm{tr}}^{\circ}$ are shown in Table 2 .

Complexation Constants with NIC A representation of the solubility data with the fitted parabola and the linear fit

Table 1. Content Uniformity and Solubility Enhancements for KET in PMs and SDs

\begin{tabular}{cccc}
\hline \hline Product & $\begin{array}{c}\text { \% Drug claimed } \\
\text { (mean } \pm \text { standard } \\
\text { deviation) }\end{array}$ & $\begin{array}{c}\text { Solubility in water at } \\
37^{\circ} \mathrm{C}(\mathrm{mg} / \mathrm{ml}) \\
(\text { mean } \pm \text { standard deviation })\end{array}$ & $\begin{array}{c}\left(S_{o}=0.044 \pm 2.0\right. \\
\mathrm{mg} / \mathrm{ml})\end{array}$ \\
\hline PM1 & $98.96 \pm 1.3$ & $0.245 \pm 0.063$ & 5.56 \\
PM2 & $99.96 \pm 1.7$ & $0.66 \pm 0.197$ & 14.98 \\
PM3 & $97.23 \pm 2.3$ & $2.34 \pm 0.75$ & 53.14 \\
PM4 & $100.29 \pm 0.54$ & $5.51 \pm 0.636$ & 125.24 \\
PM5 & $99.26 \pm 1.3$ & $9.55 \pm 0.494$ & 217.03 \\
SD1 & $98.67 \pm 2.8$ & $0.40 \pm 0.113$ & 9.06 \\
SD2 & $99.03 \pm 0.4$ & $1.14 \pm 0.021$ & 25.97 \\
SD3 & $98.19 \pm 0.6$ & $5.37 \pm 1.067$ & 122.10 \\
SD4 & $99.92 \pm 3.2$ & $11.14 \pm 1.923$ & 253.14 \\
SD5 & $100.39 \pm 1.1$ & $16.66 \pm 3.266$ & 378.62 \\
\hline
\end{tabular}


are shown in Figs. $2-5$. The complexation constants $\left(K_{1: 1}\right.$ and $K_{1: 2}$ ) were calculated along with the fit parameters from the phase-solubility data using Eqs. (4), (5), (13) and (14) and are given in Table 3.

Dissolution Studies $\mathrm{DP}_{5 \mathrm{~min}}$ (percent drug dissolved within $5 \mathrm{~min}$ ), $\mathrm{DP}_{30 \text { min }}$ values (percent drug dissolved within $30 \mathrm{~min}$ ), $\mathrm{DP}_{120 \mathrm{~min}}$ values (percent drug dissolved within $120 \mathrm{~min}$ ), $\mathrm{DE}_{10 \text { min }}$ (dissolution efficiency in $10 \mathrm{~min}$ ), $\mathrm{DE}_{120 \mathrm{~min}}$ (dissolution efficiency in $120 \mathrm{~min}$ ), relative dissolution rate for $5 \mathrm{~min}\left(\mathrm{RDr}_{5 \mathrm{~min}}\right)$ and mean dissolution time (MDT) values for different samples are reported in Table 4. In vitro dissolution profiles of pure KET, PMs and SDs over a period of $2 \mathrm{~h}$ are shown in Fig. 6.

Comparisons between the release profiles of ketoconazole

Table 2. $\Delta G_{\text {tr }}^{\circ}$ Values for the Transfer of KET from Pure Drug to Aqueous Solution of NIC

\begin{tabular}{cc}
\hline \hline \% Carrier $(\mathrm{w} / \mathrm{v})$ & $\Delta G_{\mathrm{tr}}^{\circ}(\mathrm{kJ} / \mathrm{mol})$ \\
\hline 0.1 & -3.928 \\
0.3 & -7.490 \\
0.5 & -8.767 \\
0.7 & -9.779 \\
0.9 & -10.84 \\
1.0 & -11.232
\end{tabular}

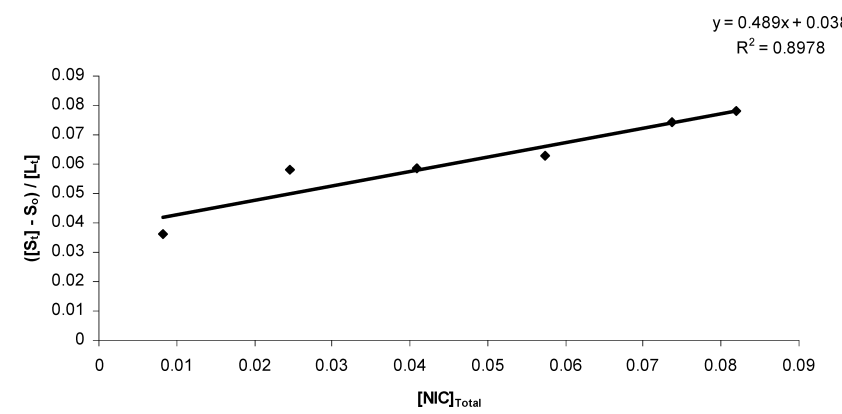

Fig. 2. Phase Solubility Profile of KET in Aqueous Solution of NIC by Linear Fit Assuming $[L] \sim\left[L_{t}\right]$

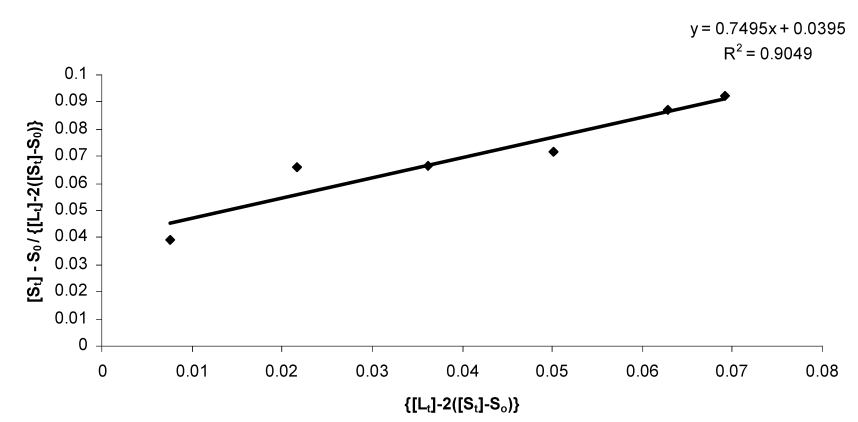

Fig. 3. Phase Solubility Profile of KET in Aqueous Solution of NIC by Linear Exact Fit

Table 3. $K_{1: 1}$ and $K_{1: 2}$ Values for KET with NIC in Triple Distilled Water from different samples were made by similarity factor $f_{2}$ and dissimilarity factor $f_{1}$. Calculated values for $f_{1}$ and $f_{2}$ are presented in Table 5.

PXRD Studies From the X-ray diffraction studies, it was observed that the crystalline peaks of nicotinamide are evident in the PMs, and in SDs (Fig. 7). The prominent peaks from pure KET at $2 \theta$ of $7.24,10.57,15.99,17.48,20.60$, 21.15 and 23.62 were clearly seen at the same position in the PMs and SDs. Both the prominent peaks of NIC existed in the PMs and SDs at their respective positions.

\section{Fourier Transform Infrared (FT-IR) Spectroscopy}

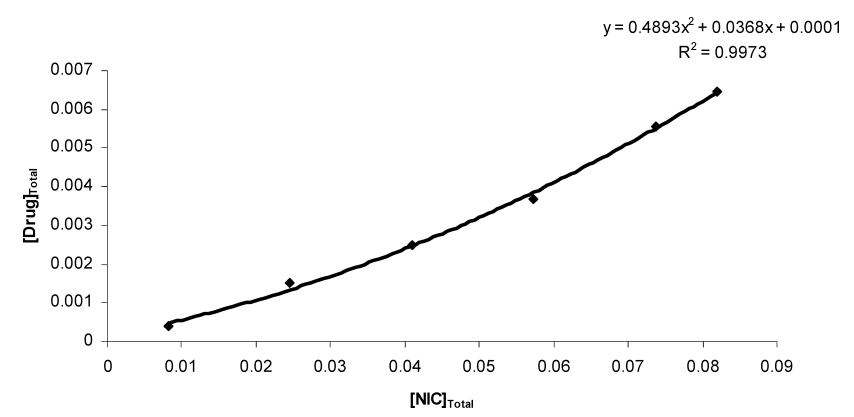

Fig. 4. Phase Solubility Profile of KET in Aqueous Solution of NIC by Parabolic Fit Assuming $[L] \sim\left[L_{t}\right]$

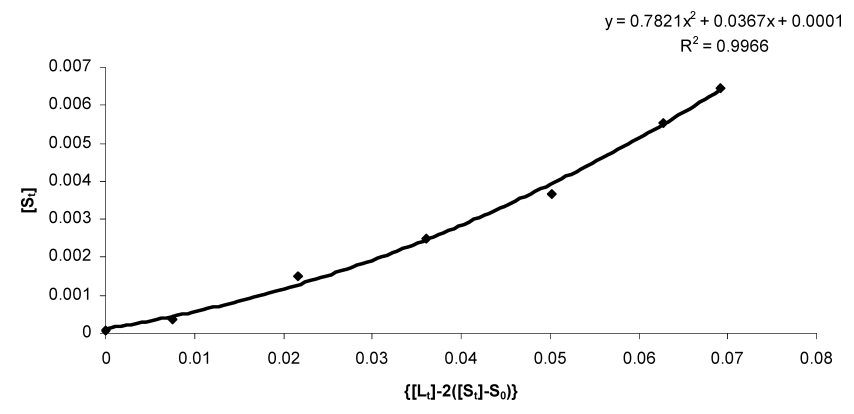

Fig. 5. Phase Solubility Profile of KET in Aqueous Solution of NIC for Exact Parabolic Fit

Table 4. Dissolution Parameters of KET and Various Compositions

\begin{tabular}{|c|c|c|c|c|c|c|}
\hline Product & $\mathrm{DP}_{5 \min }$ & $\mathrm{DP}_{30 \min }$ & $\mathrm{DP}_{120 \text { min }}$ & $\% \mathrm{DE}_{10 \text { min }}$ & $\% \mathrm{DE}_{30 \min }$ & $\mathrm{RDr}_{5 \min }$ \\
\hline KET & 3.18 & 5.35 & 6.87 & 1.183 & 2.739 & - \\
\hline PM1 & 4.35 & 5.55 & 8.89 & 2.357 & 2.842 & 1.36 \\
\hline PM2 & 5.36 & 8.59 & 17.78 & 2.968 & 4.398 & 1.68 \\
\hline PM3 & 8.09 & 12.69 & 21.67 & 4.594 & 6.526 & 2.54 \\
\hline PM4 & 11.16 & 18.61 & 35.57 & 6.301 & 9.659 & 3.50 \\
\hline PM5 & 16.46 & 25.72 & 48.72 & 9.915 & 13.53 & 5.17 \\
\hline SD1 & 5.63 & 7.33 & 12.21 & 3.82 & 3.752 & 1.77 \\
\hline SD2 & 7.11 & 11.82 & 21.89 & 4.032 & 6.072 & 2.23 \\
\hline SD3 & 12.53 & 16.88 & 27.27 & 6.821 & 8.738 & 3.94 \\
\hline SD4 & 16.85 & 25.84 & 44.06 & 9.223 & 13.59 & 5.29 \\
\hline SD5 & 22.37 & 36.50 & 55.90 & 12.952 & 19.713 & 7.03 \\
\hline
\end{tabular}

\begin{tabular}{|c|c|c|c|c|c|c|c|c|c|}
\hline \multirow{2}{*}{ Model } & \multirow{2}{*}{ Assumption } & \multicolumn{2}{|c|}{ Linear solution } & \multicolumn{2}{|c|}{ Linear fit parameters } & \multicolumn{2}{|c|}{ Parabolic solution } & \multicolumn{2}{|c|}{ Parabolic fit parameters } \\
\hline & & $K_{1: 1}\left(\mathrm{M}^{-1}\right)$ & $K_{1: 2}\left(\mathrm{M}^{-1}\right)$ & $R^{2}$ & $F$ & $K_{1: 1}\left(\mathrm{M}^{-1}\right)$ & $K_{1: 2}\left(\mathrm{M}^{-1}\right)$ & $R^{2}$ & $F$ \\
\hline Approximate & {$[L]-\left[L_{t}\right]$} & 458.94 & 12.87 & 0.8978 & 35.142 & 368 & 13.30 & 0.9973 & 1330 \\
\hline Exact & None & 458.93 & 18.25 & 0.9049 & 38.017 & 354.01 & 20.56 & 0.9966 & 853 \\
\hline
\end{tabular}




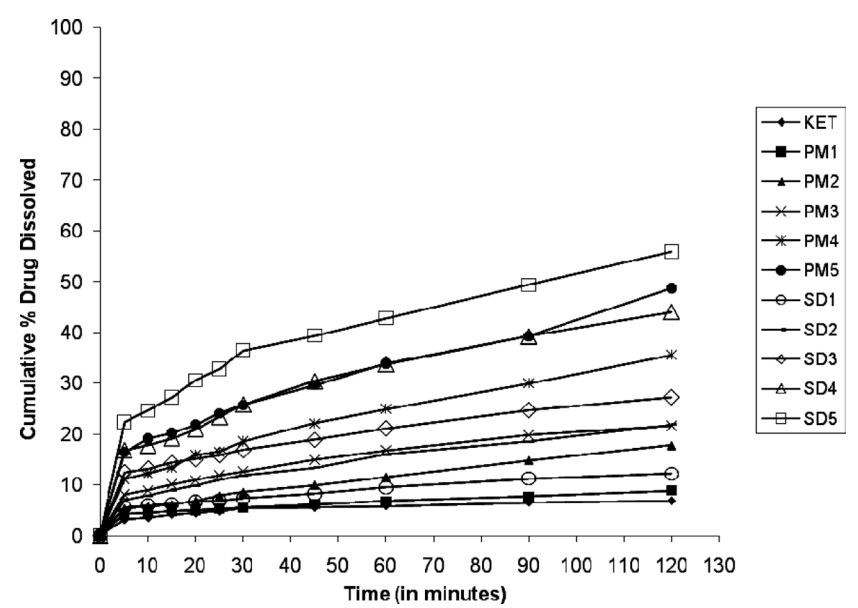

Fig. 6. Cumulative \% Drug Dissolved from Pure Drug, PMs and SDs

Table 5. $f_{1}$ and $f_{2}$ Values for the Comparison of Dissolution Profiles of SDs and PMs with Respect to Pure Drug

\begin{tabular}{cccl}
\hline \hline Composition & $f_{1}$ & $f_{2}$ & Dissolution profile \\
\hline PM1 & 14.88 & 92.39 & Similar \\
PM2 & 46.87 & 63.42 & Dissimilar \\
PM3 & 62.90 & 51.77 & Dissimilar \\
PM4 & 69.68 & 42.32 & Dissimilar \\
PM5 & 81.91 & 30.61 & Dissimilar \\
SD1 & 37.15 & 73.70 & Similar \\
SD2 & 60.13 & 53.70 & Dissimilar \\
SD3 & 71.97 & 43.48 & Dissimilar \\
SD4 & 81.41 & 31.46 & Dissimilar \\
SD5 & 86.03 & 24.43 & Dissimilar \\
\hline
\end{tabular}

The method of the FT-IR spectroscopy, in comparison to the other techniques used, was found to be the most reliable for predicting the possible interactions. Figure 8 show the FT-IR spectra of the drug, carrier, SDs and the corresponding PMs. The spectrum of pure ketoconazole showed an intense, welldefined infrared band at $\left(\mathrm{cm}^{-1}\right) 3117$ (=C-H stretch), 1646 $(\mathrm{C}=\mathrm{O}$ stretch $), 1583(\mathrm{C}=\mathrm{C}$ aromatic symmetric stretch), $1511\left(\mathrm{C}=\mathrm{C}\right.$ aromatic asymmetric stretch), 1224 and $1199\left(3^{0}\right.$ amine) and nicotinamide at $\left(\mathrm{cm}^{-1}\right) 3365$ and $3160(\mathrm{~N}-\mathrm{H}$ stretch, $1^{0}$ amine $), 1679(\mathrm{C}=\mathrm{O}$ stretch $)$ and $1617(\mathrm{~N}-\mathrm{H}$ bend, $1^{0}$ amine).

Differential Scanning Calorimetry The DSC thermograms for pure KET, NIC, their PMs and SDs are shown in Fig. 9. The DSC thermograms of KET showed apparent endothermic peak at $158.2^{\circ} \mathrm{C}$ with enthalpy of fusion $103.4 \mathrm{~J} / \mathrm{g}$. Similarly, the melting peak of NIC was observed at $137.4^{\circ} \mathrm{C}$.

\section{Discussion}

Content Uniformity Analysis SDs of drug with NIC exhibit good content uniformity and hence can be exploited for the development of a quality formulation.

Solubilization Efficiency of Nicotinamide It is clear from Table 1 that nicotinamide is a potent solubility enhancer. It can be seen that substantial improvement in the solubility was obtained for SD5. Solubility increase of more than 350-fold was obtained for this SD.

The increased solubility of PMs as compared to pure drug is ascribed to the solubilizing effect of NIC. NIC is reported to form complexes with drugs on the basis of $\pi$-electron donor acceptor mechanism. ${ }^{23)}$ Hence, the faster dissolution of KET-NIC solid dispersions is ascribed to the solubilizing effect of the carrier (nicotinamide). In addition, other factors, such as particle size reduction, absence of aggregation and agglomeration between hydrophobic drug particles, good wettablity, and dispersibility of the dispersed drug ${ }^{24}$ might have also contributed to the observed increase in the solubility of KET from SDs.

Interaction between Ketoconazole and Nicotinamide in Water The $\Delta G_{\text {tr }}^{\circ}$ values (Table 2) show whether the reaction condition is favorable or unfavorable for drug solubilization in the aqueous carrier solution. Negative $\Delta G_{\text {tr }}^{\circ}$ values indicate favorable conditions. $\Delta G_{\text {tr }}^{\circ}$ values were all negative for different NIC concentrations, indicating the spontaneous nature of KET solubilization, and decreased with an increase in NIC percentage, demonstrating that the reaction became more favorable as the concentration of NIC increased.

Complexation Constants with NIC It is evident from the solubility data (Fig. 1) that the solubility of KET was enhanced significantly by NIC and that the solubility increased in a nonlinear fashion as a function of NIC concentration. It showed a deviation from linearity, indicating an Ap type of phase solubility diagram. ${ }^{18)}$

The aromaticity ( $\pi$ system) of the pyridine ring in NIC may be the main contributing factor in the nonlinear solubility behavior of KET in the presence of NIC.

From the data shown in Figs. 2-5 and given in Table 3, it is clear that at lower concentrations, NIC undergoes formation of $1: 1$ complex while at higher concentrations $1: 2$ complexation occurs.

The linear solution was best represented by the fit of the exact equation as determined from the $R^{2}$ and $F$ fit parameters whereas the parabolic solution was best represented by the fit of approximate equation.

In addition, comparison of the parabolic fits versus the linear fits shows clearly that the data were best represented by the parabolic regression method. Both the multiple $R^{2}$ and $F$ statistical fit parameters were significantly better in the parabolic fits. In this analysis, one can conclude that the complexation constants determined from the parabolic fit of the data were the most accurate.

In summary, the solubility of KET is enhanced by complexation with NIC. The complexation is via formation of $1: 1$ and $1: 2$ complexes between KET and NIC. The use of the approximate solution was appropriate in this case because $[L] \sim\left[L_{t}\right]$. An exact solution of the equation with no approximation was derived for use when $[L]$ can not be approximated by $\left[L_{t}\right]$. The parabolic fit was a more accurate way of representing complexation than a linear representation of the data. The apparent low value of $K_{1: 2}$ with respect to $K_{1: 1}$ indicates that the $1: 1$ complex is the predominant form.

Dissolution Studies The dissolution characteristics of oral formulations should be evaluated using test media within the physiologic $\mathrm{pH}$ range of $1.2-6.8$. To simulate intestinal fluid (SIF), a dissolution medium of $\mathrm{pH} 6.8$ should be employed. Zhou et al. reported that by increasing the $\mathrm{pH}$ of the dissolution medium from 1.2 to 6.8 the extent of dissolution of ketoconazole reduces because ketoconazole is a dibasic drug and is best absorbed at highly acidic levels. ${ }^{25)}$ So, simulated intestinal fluid of $\mathrm{pH} 6.8$ was used for this 
(J)

(I)

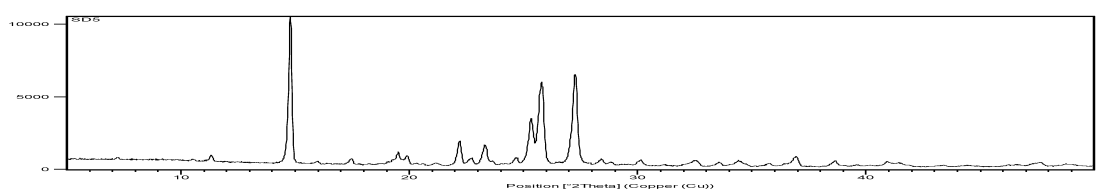

(H)
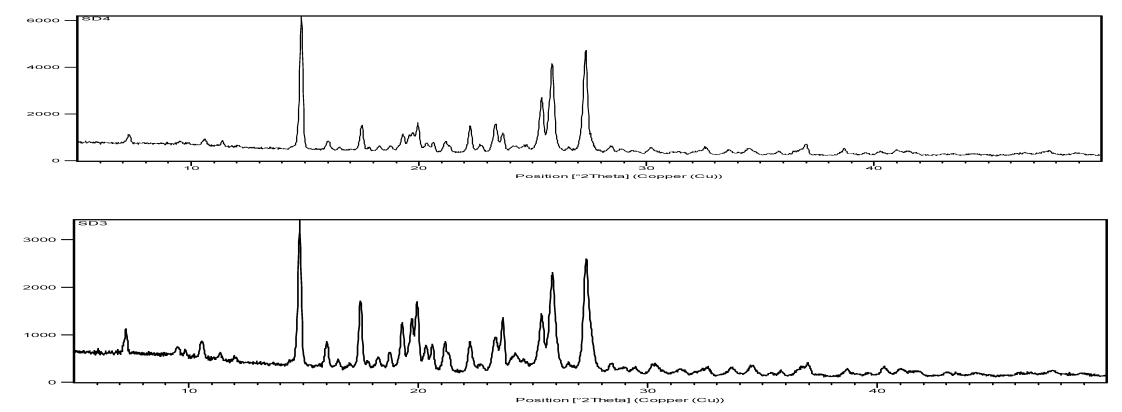

(G)

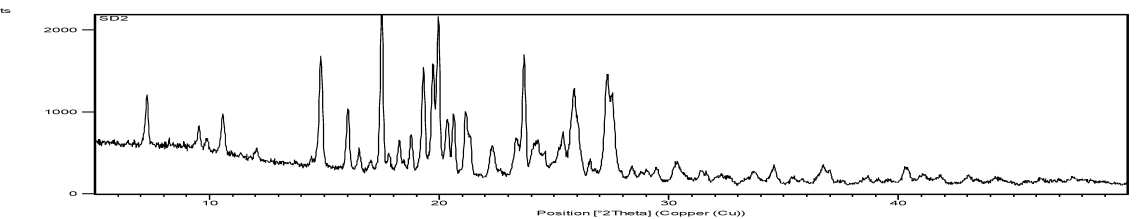

(F)

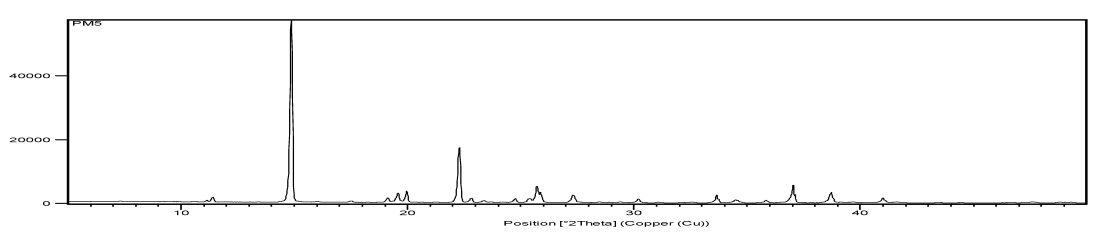

(E)

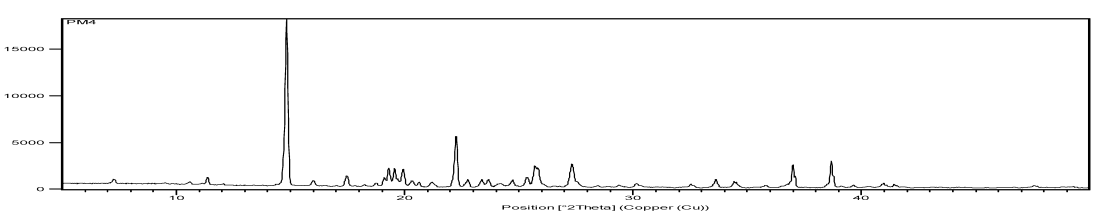

(D)

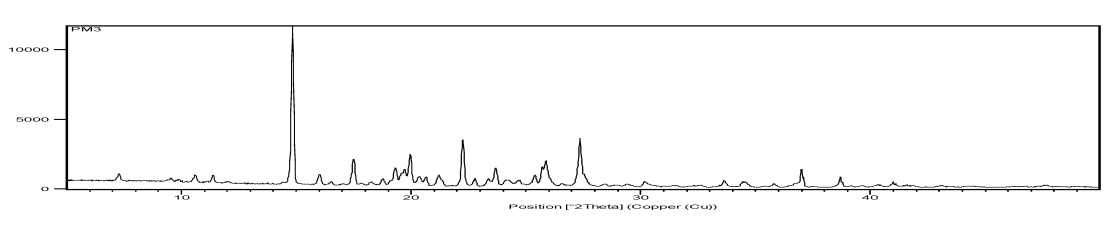

(c)

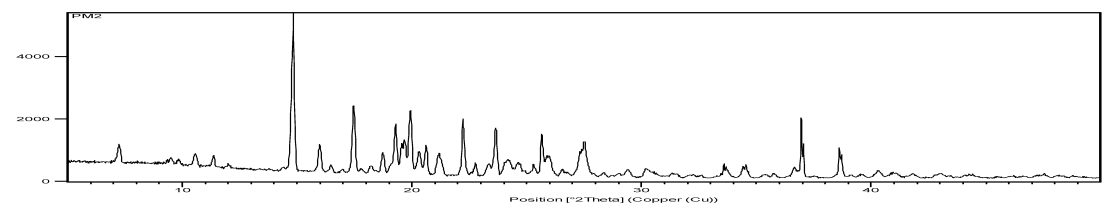

c)

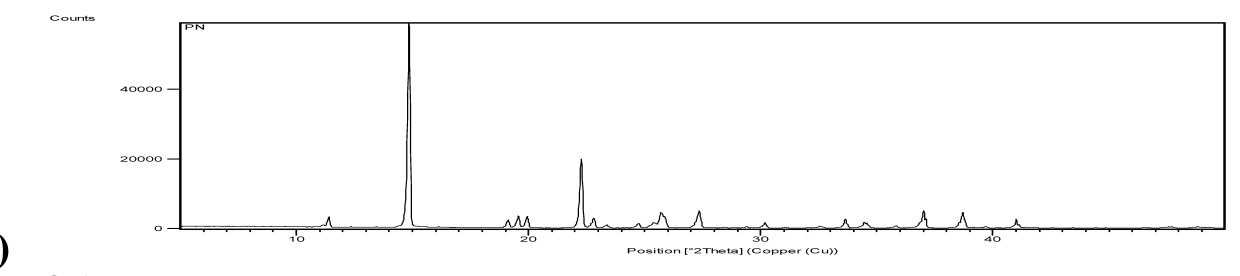

.

(B)

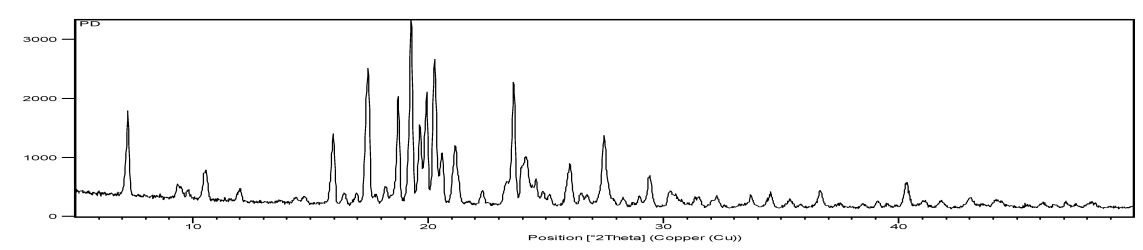

Fig. 7. Powder X-Ray Diffractograms of (A) KET, (B) NIC, (C) PM2, (D) PM3, (E) PM4, (F) PM5, (G) SD2, (H) SD3, (I) SD4 and (J) SD5 
(J)

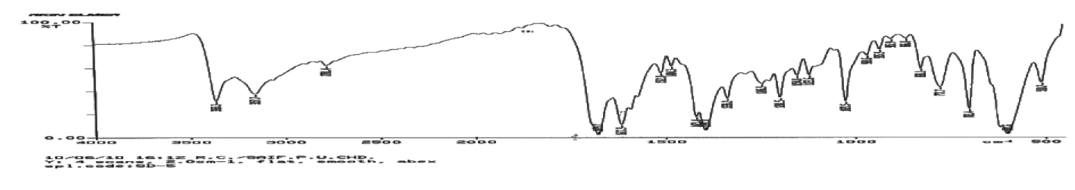

(I)

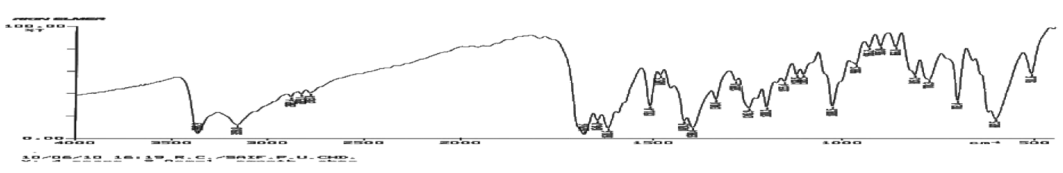

(H)

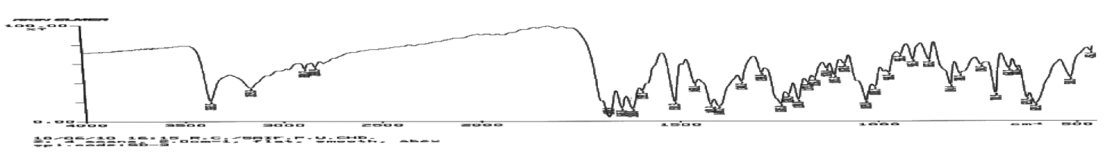

(G)

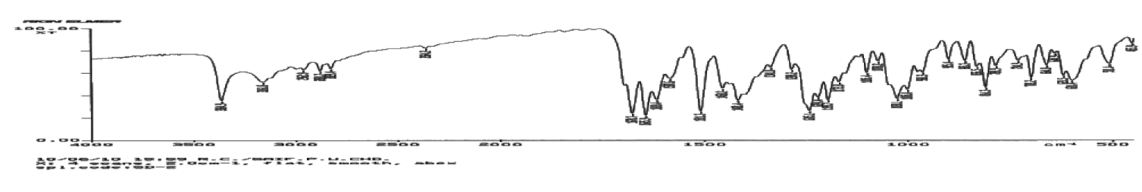

(F)

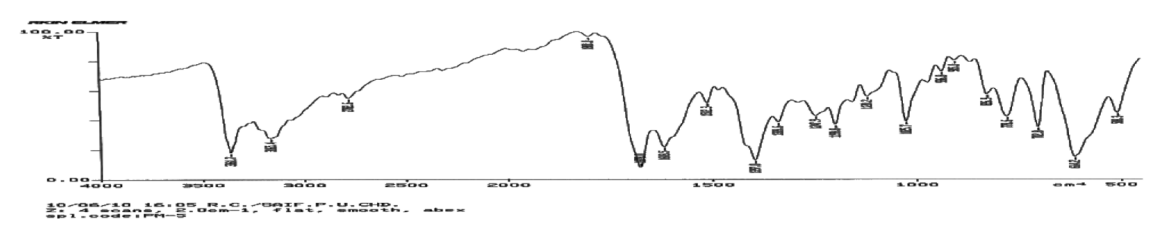

(E)

(D)

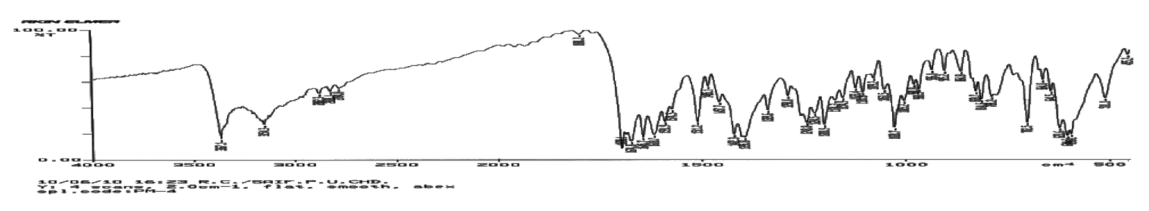

(C)

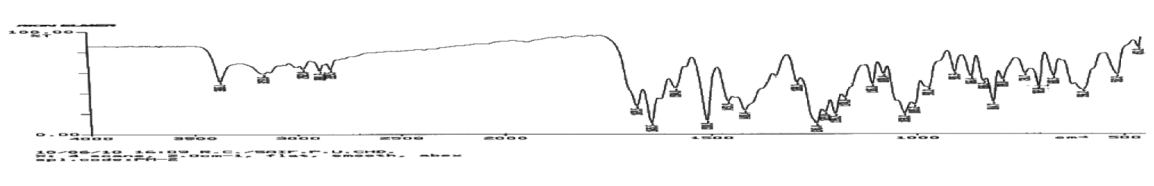

(B)

(A)
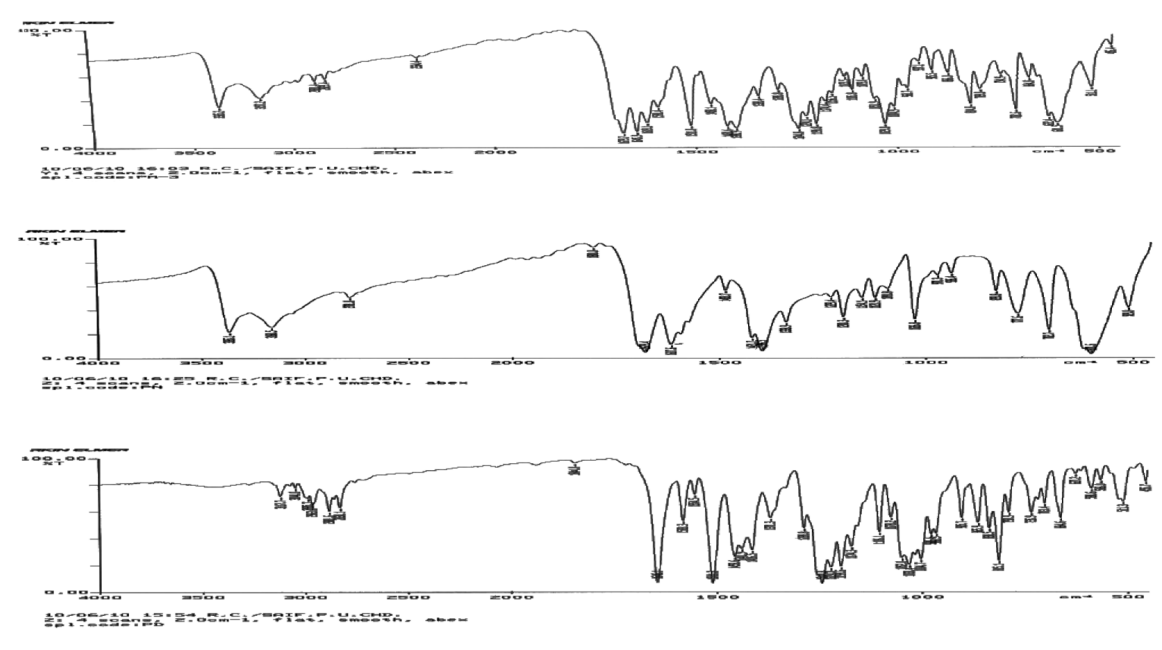

Fig. 8. FT-IR Spectra of (A) KET, (B) NIC, (C) PM2, (D) PM3, (E) PM4 (F) PM5, (G) SD2, (H) SD3, (I) SD4 and (J) SD5 
636

Vol. 59, No. 5

(L)

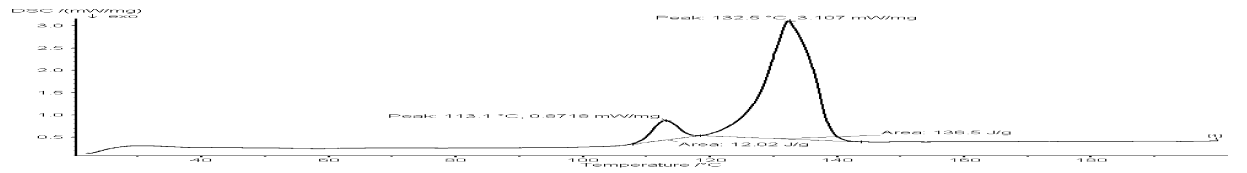

(K)

(J)

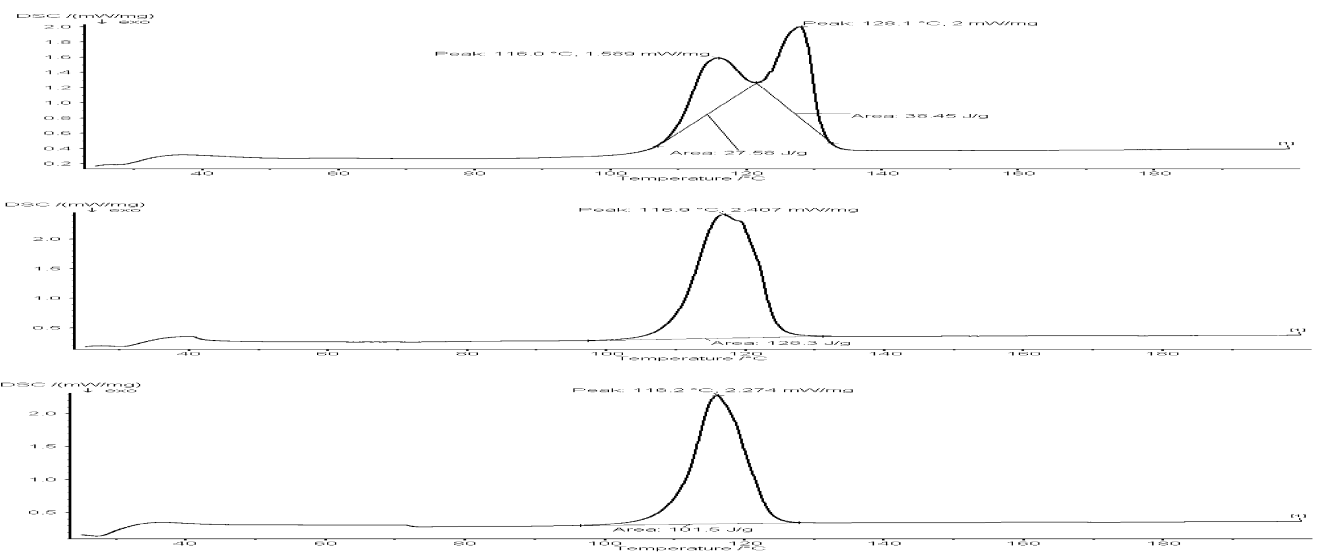

(I)

(H)

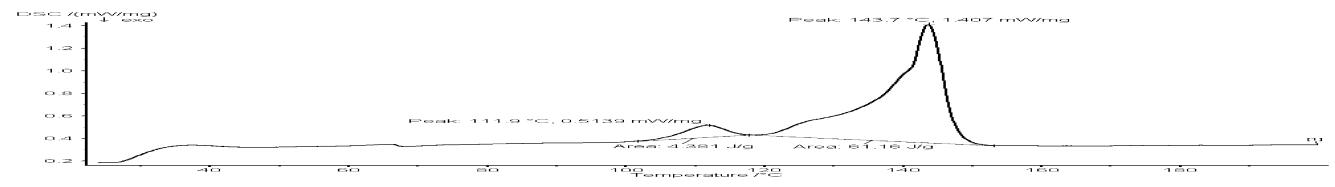

(G)

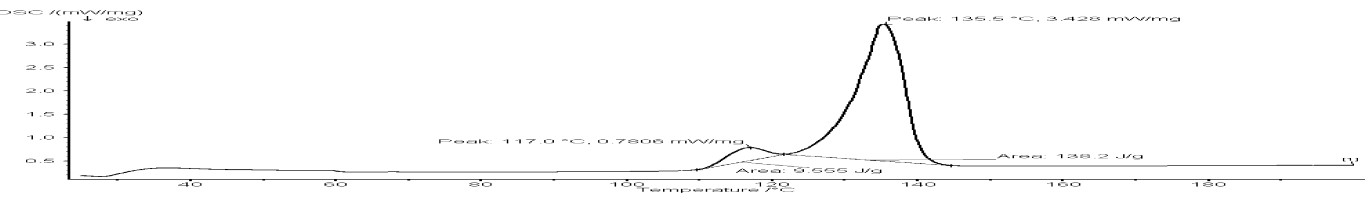

(F)

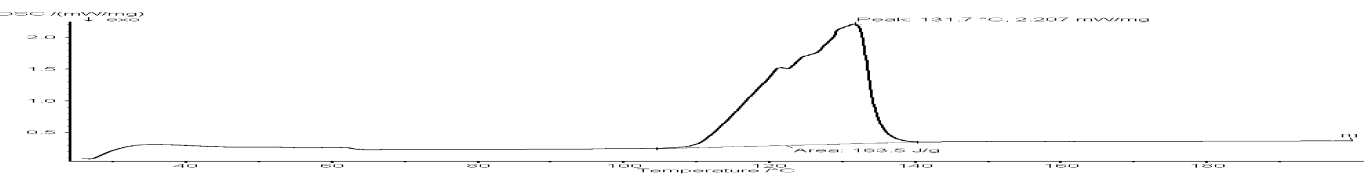

(E)

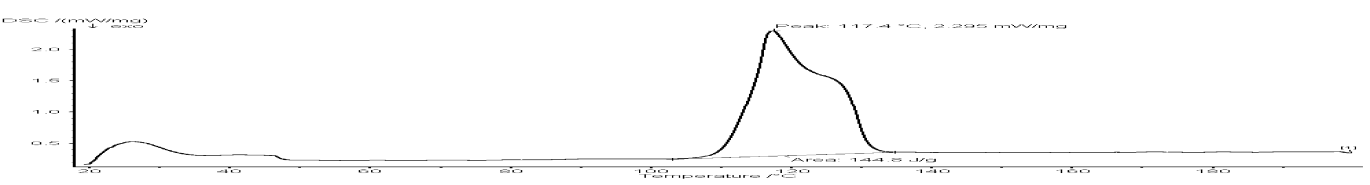

(D)

(C)

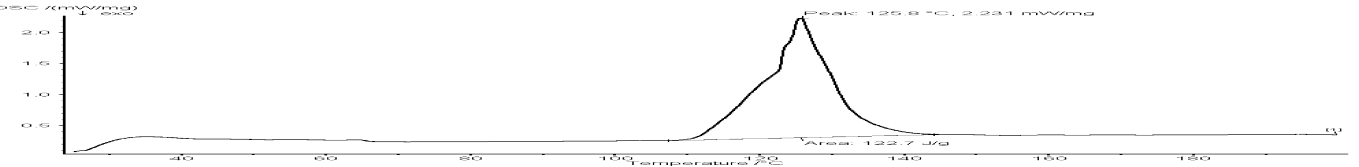

(B)

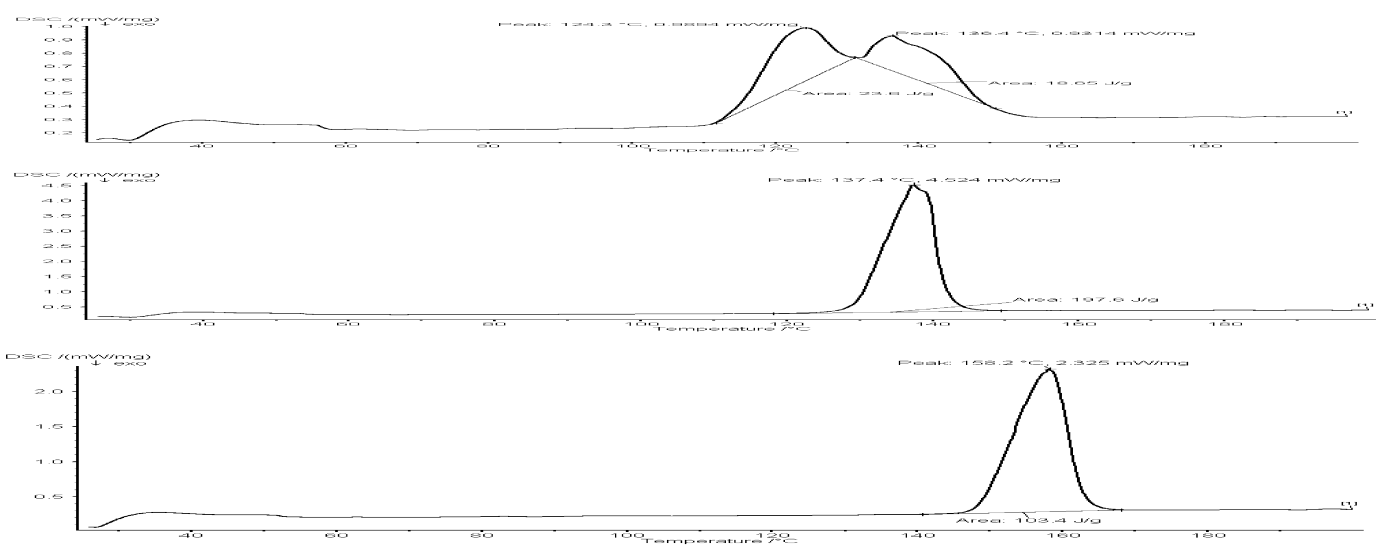

(A)

Fig. 9. DSC Thermograms of (A) KET, (B) NIC, (C) PM1, (D) PM2, (E) PM3, (F) PM4 (G) PM5, (H) SD1, (I) SD2, (J) SD3, (K) SD4 and (L) SD5 
study. Because, if the dissolution rate is improved at $\mathrm{pH} 6.8$, then it will also improve at lower $\mathrm{pH}$.

From data presented in Table 4 and Fig. 6, it is evident that the dissolution rate of pure KET was very low $\left(\mathrm{DP}_{5 \mathrm{~min}}\right.$ $3.18 \%, \mathrm{DP}_{30 \min } 5.35 \%, \mathrm{DE}_{10} 1.18 \%$, and $\mathrm{DE}_{120}$ 3.51) with less than $10 \%$ drug dissolved after $2 \mathrm{~h}$ dissolution studies. As the proportion of NIC in the PMs and SDs increased, there was a progressive increase in the dissolution rate of the drug. ${ }^{10)}$ The highest improvement was obtained in SD5. Based on $\mathrm{DP}_{30 \text { min }}$ values, SD5 showed 6.8-fold increase in dissolution rate than the pure KET in $\mathrm{pH}$ 6.8. Dissolution efficiency of the dispersion also improved from 1.18\% $\left(\mathrm{DE}_{10}\right)$, and $3.51 \%\left(\mathrm{DE}_{120}\right)$ for pure drug to $6.82 \%\left(\mathrm{DE}_{10}\right)$, and $31.74 \%\left(\mathrm{DE}_{120}\right)$ in $\mathrm{pH} 6.8$ and the cumulative percentage of drug dissolved after $2 \mathrm{~h}$ study was $55.9 \%$. From the results of the dissolution parameters (Table 4), it can be easily noted that the dissolution rate of KET from the PMs and SDs was remarkably enhanced compared with the pure drug alone.

The increase in the dissolution rate of KET in the PMs is attributed to a local solubilization effect, produced by the NIC in the diffusion layer immediately surrounding the drug particles. Whereas, the enhancement in the drug dissolution rate from the SDs is probably due to an increase in the surface area of the drug exposed to the dissolution medium. This increase in the surface area is caused by the smaller particle size reached for the KET into the SDs. Undoubtedly, other factors such as wettability and reduced aggregation, have also contributed to the dissolution enhancement to some extent. $^{26)}$

The dissolution profile of pure drug was dissimilar to those of batches PM2, PM3, PM4, PM5, SD2, SD3, SD4 and SD5 when calculated using dissimilarity $\left(f_{1}\right)$ and similarity $\left(f_{2}\right)$ factors (Table 5). It was observed that the dissolution profile of PM1 and SD1 could be considered equivalent to pure drug because in these compositions the amount of carrier was not sufficient to increase the dissolution rate.

PXRD Studies The major crystalline peaks were similar in the PMs and SDs (Fig. 7), and no new peaks could be observed, thereby ruling out the drug-carrier interaction in the solid state. ${ }^{27)}$ Although NIC exhibited high interaction with KET in the aqueous phase, as manifested by its high solubilizing capacity, XRD patterns taken from the different samples have provided us information enough concerning the lack of solid-state interaction between KET and NIC. These observations have proved that KET remains unalterable after its manufacturing as SDs and NIC does not modify the crystalline structure of KET. Thus, the existence of a solid-solid solution in these systems can be discarded. Based on the fact that there is no evidence of interaction between KET and NIC, ketoconazole presents a total chemical stability after its preparation as SDs. ${ }^{10)}$

The crystallinity of the complex in PMs and SDs is remarkably reduced compared with the two individual components. The reduction of the crystallinity of the complex is associated with solubility enhancement of poorly soluble drugs. The crystallinity decreased with increase in percentage of NIC. Although the decrease in the crystallinity of the PMs is due to the dilution of KET with NIC, the crystallinity of SDs decreased more than those of PMs of the same quantity of NIC. Relative reduction of diffraction intensity of KET in NIC dispersion vis-à-vis physical mixtures at these angles suggests that either the quality of the crystals is reduced, or a change is induced in the crystal orientation, or some of the drug is still present in crystalline form.

Fourier Transform Infrared (FT-IR) Spectroscopy The results shown in Fig. 8 depicted that there was no significant change in the spectrum of SDs, as incorporation of KET into NIC did not modify the position of its functional groups. IR spectra of pure KET and its PMs and SDs were found to be identical. A decrease in the intensity of KET peaks was observed with the increasing amount of NIC. Presence of the stretching vibration of KET carbonyl peak in SDs and PMs indicates that the drug crystalline form was not completely lost during solid dispersion formation and its attenuated intensities could be due to the lower drug content. Therefore, the absence of major shift in the peak positions, retention of drug peak and the almost equivalent addition spectra (of KET and NIC) for SDs and PMs suggested the absence of interactions in the solid state between NIC and KET. Thus the NIC-KET complexes belong to a category that exhibits complete miscibility in the liquid state and complete immiscibility in the solid state. ${ }^{27,28)}$ These results are supported by the results of PXRD.

Differential Scanning Calorimetry As shown in Fig. 9, thermograms of the mixtures containing an excess amount of KET demonstrated two endothermic transitions. The first transition peaked very close to the NIC melting temperature; the second transition corresponding to the drug melting gradually shifted to the lower temperature and broadened, loosing its sharp, distinctive appearance. In SD1, a sharp peak was found at $143.7^{\circ} \mathrm{C}$ with enthalpy of fusion $61.16 \mathrm{~J} / \mathrm{g}$. Similarly, another broad reduced endotherm was observed at $111.9^{\circ} \mathrm{C}$. PM1 showed a sharp peak at $136.4{ }^{\circ} \mathrm{C}$ with an enthalpy of fusion $18.65 \mathrm{~J} / \mathrm{g}$ and another broad fused peak at $124.3^{\circ} \mathrm{C}$. As the drug carrier ratio further decreased, at the KET-NIC ratio of $70: 30$, the DSC curves showed only one endothermic peak corresponding to the melting of carrier.

Absence or shifting towards the lower melting temperature of the drug peak in SDs and PMs indicated the possibilities of interactions between KET and NIC. But, in a binary solid system such as a crystalline drug and a crystalline carrier, if the drug is soluble in the molten carrier at the melting temperature of the carrier or vice versa, then this drug and the carrier form a eutectic system. ${ }^{29-31)}$ KET has been shown to form eutectics with NIC at around $70 \% \mathrm{w} / \mathrm{w}$ concentration in the mixture. As the melt of any composition other than that corresponding to the eutectic is cooled during the preparation of SDs, one component will progressively solidify, thereby rendering the remaining liquor richer in the other component until the eutectic composition is reached, and at that point, the remaining liquid will solidify as a fine dispersion. Therefore, KET eutectic crystallization results in well defined microstructure with a reduction in drug particle size.

With further decrease in drug concentration i.e. at the drug polymer ratio of $50: 50$ (SD3 and PM3), the single endothermic peak displayed a shoulder and the system started to have fusion temperatures higher than the eutectic temperature. Similar results were shown by ibuprofen-PEG solid dispersions. $^{32)}$

The DSCs of SD4 and PM4 exhibited two endothermic events. The peaks at $116.0^{\circ} \mathrm{C}$ in SD4 and a shoulder at lower temperature over the broad peak at $131.7^{\circ} \mathrm{C}$ in PM4 are the 
melting endotherm of eutectic. After the eutectic has melted, the solid phase suspended in the liquid melt might be NIC (whose concentration might have exceeded the eutectic composition), which melted at a temperature lower than the pure NIC to produce the second peak, the reduced broad fusion peaks at $128.1^{\circ} \mathrm{C}$ in SD4 and $131.7^{\circ} \mathrm{C}$ in PM4. This might be due to the presence of a small amount of KET as an impurity which might have caused the melting point depression of NIC. Similar results were shown by ibuprofen poloxamer 407 solid dispersions. ${ }^{28)}$

\section{Conclusion}

The solid dispersions of ketoconazole with nicotinamide were prepared in different weight ratios using melting method. Solubility studies showed a solubilizing effect of nicotinamide on ketoconazole. The negative values of the Gibbs free energy of transfer for ketoconazole from water to an aqueous solution of nicotinamide indicate the spontaneity of the transfer. FT-IR, DSC, and X-ray diffraction spectroscopic studies indicate that there was no chemical interaction between ketoconazole and nicotinamide in the solid state similar to that of ketoconazole and mannitol ${ }^{33)}$ which confirms the stability of drug in its solid dispersion. The highest improvement in solubility and in vitro drug release was observed in SD4.

\section{References}

1) Levine H. B., "Ketoconazole in the Management of Fungal Disease," Adis Press, New York, 1982.

2) Gallia E., Nicolaides E., Horter D., Lobenberg R., Reppas C., Dressman J. B., Pharm. Res., 15, 698-705 (1998).

3) Baxter J. G., Brass C., Schentag J. J., Slaughter F. L., Pharm. Res., 75, 443-447 (1986).

4) Chiou W. L., Riegelman S., J. Pharm. Sci., 60, 1281-1302 (1971).

5) Ford J. L., Pharm. Acta Helv., 61, 69-88 (1986).

6) Van den Mooter G., Wuyts M., Blaton N., Busson R., Grobet P., Augustijns P., Kinget R., Eur. J. Pharm. Sci., 12, 261-269 (2001).

7) Esclusa-Diaz M. T., Gayo-Otero M., Perez-Marcos M. B., Vila-Jato J. L., Torres-Labandeira J. J., Int. J. Pharm., 142, 183-187 (1996).

8) Rasool A. A., Hussain A. A., Dittert L. W., J. Pharm. Sci., 80, $387-$ 393 (1991).
9) Truelove J., Bawarshi-Nassar R., Chen N., Hussain A., Int. J. Pharm., 19, 17-25 (1984).

10) Varma M. M., Pandy J. K., Drug Dev. Ind. Pharm., 31, 417-423 (2005).

11) Lee J., Lee S. C., Acharya G., Chang C., Park K., Pharm. Res., 20, 1022-1030 (2003).

12) Lim L., Go M., Eur. J. Pharm. Sci., 10, 17-28 (2000).

13) Bogdanova Sv., Sidzhakova D., Karaivanova V., Georgieva Sv., Int. J. Pharm., 163, 1-10 (1998).

14) Eshra A., Naggar V., Boraie N., Pharmazeutische Industrie, 48, $1557-1560$ (1986)

15) Hamza Y., Sammour O., Abdel Latif H., Pharmazeutische Industrie, 56, 286-291 (1994).

16) Verma M. M., Kumar M. T., Balasubramaniam J., Pandit J. K., Bollettino Chimico Farmaceutico, 141, 176-180 (2002).

17) Coffman R. E., Kildsig D., Pharm. Res., 13, 1460-1463 (1996).

18) Higuchi T., Conners K. A., Adv. Anal. Chem. Instrum., 4, 117-212 (1965).

19) Rescigno A., Pharm. Res., 9, 925-928 (1992).

20) Pillay V., Fassihi R., J. Pharm. Sci., 88, 843-851 (1999).

21) Moore J. W., Flanner H. H., Pharm. Tech., 20, 64-74 (1996)

22) Ibrahim H. M., J. Pharm. Sci., 74, 575-577 (1985).

23) Fawzi M., Davison E., Tute M., J. Pharm. Sci., 69, 104-105 (1980).

24) Chowdary K. P. R., Rao P. V., Drug Dev. Ind. Pharm., 20, 3015-3022 (1994).

25) Zhou R., Moench P., Heran C., Lu X., Mathias N., Faria T. N., Wall D. A., Hussain M. A., Smith R. L., Sun D., Pharm. Res., 22, 188-192 (2005).

26) Gins J. M., Arias M. J., Moyano J. R., Sdnchez-Soto P. J., Int. J. Pharm., 143, 247-253 (1996).

27) Ahuja N., Katare O. P., Singh B., Eur. J. Pharm. Biopharm., 65, 2638 (2007).

28) Newa M., Bhandari K. H., Oh D. H., Kim Y. R., Sung J. H., Kim J. O., Woo J. S., Choi H. G., Yong C. S., Arch Pharm. Res., 31, 1497-1507 (2008).

29) Carstensen J. T., "Advanced Pharmaceutical Solids," Marcel Dekker, New York, 2001, pp. 170-189.

30) Law D., Wang W., Schmitt E. A., Michelle A. L., Pharm. Res., 19, $315-321$ (2002).

31) Sudha R. V., Zeren W., Stefanie H., Steven L. K., J. Pharm. Sci., 96, 294-304 (2007).

32) Khan G. M., Jiabi Z., Drug Dev. Ind. Pharm., 24, 455-462 (1998).

33) Pandey S., Viral D., Goyani M., Pandey D., Der. Pharmacia Lett., 1, $18-24$ (2009). 